Part VIII

Community as Lived 



\section{Part VIII}

\section{Community as Lived}

Royce was an idealist in the vernacular sense of that word as well as in its technical and philosophical reference. He was sensitive to the charge that philosophical idealism was essentially an unpractical doctrine. For Royce, such a criticism failed to comprehend that "loyalty is the practical aspect and expression of an idealistic philosophy." (RQP, p. vii. $)^{1}$

The essays contained in this section, although simply written, evoke many of the major themes of Royce's thought, especially those dealing with the nature of the community. Of particular fascination is Royce's development of the meaning of provincialism. Royce defined the meaning of one's province as primarily a domain, sufficiently unified, geographically and socially to generate a sense of pride and identity for its inhabitants. (RQP, p. 6I; below, 2: 1069). In The Philosophy of Loyalty, he called for a "new and wiser provincialism," as distinguished from a "mere renewal of the old sectionalism." (PL, p. 245; above, 2:953.) In Royce's view, the idealization of the "provincial" experience would aid in the resolution of a serious "American problem," namely, "the problem of educating the self-estranged spirit of our nation to know itself better." (PL, p. 245; above, 2:952.)

Royce sees no contradiction in the deepening of "provincial" experience as a way of fostering an enhanced sense of national life. Actually, he holds that "they cannot prosper apart." (RQP, p. 66;

${ }^{1}$ Cf. also Royce's comment that "Professor James' pragmatism despite its entertaining expressions of horror of the eternal, actually does state one aspect of eternal truth. It is, namely, that all search for truth is a practical activity, with an ethical purpose, and that a purely theoretical truth, such as should guide no significant active process, is a barren absurdity." ( $P L$, p. 326 ; above, $2: 984$.) 
below, 2: 107 r.) And the possibility of an international, "great community," depends likewise on the participating presence of nations, thoroughly self-conscious in their own right. It is not loyalty to a cause which Royce fears as the source of tension and unrest. To the contrary, it is the individual without roots, without commitment, and without care, who dilutes the energies necessary to build a community. Further, when under duress, the "detached individual or nation" often abandons restraint and out of disrespect for the variety of life-styles, moves to suppress them.

In one of his last writings, Royce warns us that we must avoid the plight of the "detached individual," who belongs "to no community which he loves and to which he can devote himself. . . . For mere detachment, mere self-will, can never be satisfied with itself, can never win its goal. What saves us on any level of human social life is union." (HGC, pp. $5^{1-52}$; below, $\left.2: 1156\right)$. 